\title{
EXAMINING THE IMPACT OF ONLINE CASE-BASED DISCUSSIONS ON STUDENTS' PERCEIVED COGNITIVE PRESENCE, LEARNING AND SATISFACTION
}

\author{
Ayesha Sadaf and Stella Kim \\ University of North Carolina Charlotte, \\ 9201 University City Blvd, Charlotte, NC 28223, USA
}

\begin{abstract}
This study examined the impact of case-based discussions on students perceived cognitive presence, learning and satisfaction in online courses. Forty-four online graduate students enrolled in an instructional design course completed an online survey. The quantitative data were analyzed using descriptive statistics and a paired-samples t-test. Qualitative data obtained from the open-ended survey responses were analyzed using constant comparative approach. The findings revealed that case-based discussions lead to high levels of cognitive presence-Triggering, integration, and resolution-than non-case-based discussion. In addition, students have a higher level of perceived satisfaction in case-based discussion than non-case-based discussions.
\end{abstract}

\section{KEYWORDS}

Cognitive Presence, Case-Based Discussions, Online Courses, Online Learning

\section{INTRODUCTION}

The importance of cognitive presence to generate higher-level learning in online environments has been widely reported in literature (Garrison, Anderson, \& Archer 2001; Rourke \& Kanuka 2009; Sadaf \& Olesova, 2017). Garrison, Anderson, and Archer (2001) defined cognitive presence as "the extent to which learners are able to construct and confirm meaning through sustained reflection and discourse in a critical community of inquiry" (11). The concept of cognitive presence emerged from the Community of Inquiry (CoI) framework to guide the use of online learning environments in support of social constructivist approach to learning. Case studies hold great potential for facilitate constructivist learning through social interactions in online courses. However, little is known about online case-based discussions and their impact on cognitive presence and student learning in online courses. Therefore, the purpose of this study is to implement case-based discussions and evaluate its impact on students' cognitive presence, perceived learning and satisfaction in online courses. A quantitative research method was used for the evaluation and qualitative data were used to further explain the findings obtained from the quantitative data. The results of this study will enhance the quality of teaching and learning strategies used in online courses and provide guidelines for instructors looking to enhance cognitive presence in their online courses using online case-based discussions.

\section{LITERATURE REVIEW}

Given the recent rapid growth of online education, identifying "best practices" for facilitating student learning in online environments has gained considerable interest (Nistor \& Neubauer, 2010). Studies have reported the effectiveness of online discussions, specifically, case-based discussions to improve student learning (Ertmer \& Koehler, 2014; Sadaf \& Olesova, 2017). Case-based discussions are the type of discussion that can introduce students to real-world scenarios where they can exchange opinions and interact with each other to find solutions to the problem in the case. On the other hand, non-case-based or 
conventional discussion are defined as posting of a question about a particular topic of discussion and asking student to respond in the context of the course (Darabi, Liang, Suryavanshi, \& Yureki, 2013).

Case-based discussions introduce students to diverse perspectives and enrich the learning experience by promoting understanding, reflection, elaboration, and clarification (Ertmer \& Stepich, 2002; Yew \& Schmidt, 2012). During case-based instruction, students collaborate and discuss case elements with other students (Ertmer \& Koehler, 2014). In a meta-analysis on effectiveness of online discussion strategies, Darabi and colleagues (2013) stated that students usually respond better when they are engaged in a purposefully structured and strategic online discussion, especially when discussion tasks involved an application scenario such as a case. Online case-based discussions have the potential to enhance cognitive presence in online courses through application of real-world scenarios across different disciplines. Although case-based discussions can help facilitate high-level learning (Darabi et al., 2013; Ertmer \& Koehler, 2014; Richardson, Sadaf, \& Ertmer, 2012) research related to their impact on student cognitive presence is limited.

\subsection{Purpose of the Study}

The purpose of this study was to examine the impact of case-based discussions on students' cognitive presence in online courses. The overall question that guided our study was this: To what extent do case-based discussions compare with non-case-based discussions impact students' levels of cognitive presence in online discussions? Specifically, our research questions included the following:

1. Is there a difference in the overall cognitive presence in online case-based and non-case-based discussions?

2. Are there differences between case-based and non-case-based discussions in terms of the impact of cognitive presence, satisfaction and perceived learning?

\section{METHODS}

\subsection{Participants}

A purposeful sample of forty-four graduate students (11 males and 32 females) enrolled in an Instructional Design course were selected to participate in this study. The sample was majority female $(75 \%, \mathrm{n}=32$; male: $25 \%, \mathrm{n}=11)$ and half $(50 \%, \mathrm{n}=22)$ of them were more than 40 years old. The majority $(59 \%, \mathrm{n}=26)$ of the participants have taken more than 3 online courses. All of the participants rated themselves as being very comfortable with participating in online discussions.

\subsection{Context of the Study}

The online course was offered over a 15 -week semester and delivered via a learning management system, Canvas. Students were required to engage in week-long online discussions per week. During the semester, there were thirteen online discussions on various topics-three case-based discussions and ten non-case-based discussions. The case-based discussions consisted of decision-making problems referred by Jonassen (2010) as a rational choice model, in which a group of students must compare the advantages and disadvantages of alternative solutions of the problems. Each case described a scenario in which a specific instructional design principle was applied to solve the issue. Students were required to analyze the problem situations, reflect on the concepts learned in the course and propose solutions to the issues presented in the case study.

\subsection{Data Collection and Analysis}

Data were collected from an online survey administered at the end of Fall 2018, Spring 2019, and Fall 2019 semesters. Students responded to two sets of CoI survey questions: one with a reflection on their case-based discussions experience and the other on the non-case-based discussions. Students' perceived learning and satisfaction were measured by adding two survey items at the end. The CoI survey was developed to measure 
students' perception of cognitive presence, teaching presence, and social presence (Arbaugh et al., 2008). Since the focus of this study is cognitive presence, only 12 items form the CoI survey that measure cognitive presence were used. The items employed a 5-point Likert-type scale, with $1=$ strongly disagree and $5=$ strongly agree. Simple demographic information was also collected such as gender, age, and prior experience with online courses. In addition, qualitative data were sought using open-ended questions in order to further explain the quantitative findings.

The quantitative data were analyzed descriptive analysis using means and standard deviations. To examine the difference between case-based and non-case-based discussions, a paired t-test was be performed for each variable separately. Qualitative data from the open-ended survey responses were analyzed using constant comparative approach (Miles \& Huberman, 1994).

\section{RESULTS}

Results showed, in general, students' cognitive presence was higher for the case-based discussions than the non-case-based discussions for all four levels of cognitive presence-Triggering, exploration, integration, and resolution. Students' perceptions of their cognitive presence in online case-based discussions showed that students had high perceptions of their cognitive presence related to both integration $(M=4.11, S D=0.83)$ and resolution $(M=4.21, S D=0.76)$ compared with the non-case-based discussions. Additionally, students were more satisfied $(M=4.09, S D=.77)$ and learned more $(M=4.00, S D=0.84)$ as compared to non-case-based discussions (see Table 1).

Table 1. Students' level of cognitive presence in case-based and non-case-based discussions $(n=43)$

\begin{tabular}{lllll}
\hline \multirow{2}{*}{$\begin{array}{l}\text { Levels of Cognitive Presence } \\
\text { Case-based discussions }\end{array}$} & \multicolumn{3}{c}{$\begin{array}{l}\text { Non-case-based } \\
\text { discussions }\end{array}$} \\
\cline { 2 - 5 } & Mean & $S D$ & Mean & $S D$ \\
\hline Triggering Event & 4.07 & 0.66 & 3.84 & 0.78 \\
Exploration & 4.00 & 0.71 & 3.95 & 0.73 \\
Integration & 4.11 & 0.72 & 3.97 & 0.76 \\
Resolution & 4.20 & 0.70 & 4.02 & 0.79 \\
I was satisfied with the discussions & 4.09 & 0.77 & 3.80 & 0.82 \\
I learned much in the discussions & 4.00 & 0.84 & 3.91 & 1.01 \\
\hline
\end{tabular}

The paired-samples t-test was conducted to explore the difference in the cognitive presence between case-based and non-case-based discussions. Among four levels of the cognitive presence, there were statistically significant differences in triggering events, integration, and resolution. More specifically, a higher rating was found on triggering events for case-based discussion $(M=4.0758, S D=.6623)$ than non-case-based discussion $(M=3.8409, S D=.7858), t(43)=2.907, \mathrm{p}<.01$. Also, students' responses to integration showed statistically significant higher scores on case-based discussion $(M=4.1061, S D=.7288)$ than non-case-based discussion $(M=3.9697, S D=.7602), t(43)=2.148, \mathrm{p}<.05$. Students' responses to resolution revealed significantly higher scores on case-based discussion $(M=4.2045, S D=.7052)$ than non-case-based discussion $(M=4.0227, S D=.7921), t(43)=2.253, \mathrm{p}<.05$. The second cognitive level, exploration, only exhibited a statistically non-significant difference between case-based discussion $(M=4.0076, S D=.7170)$ and non-case-based discussion $(M=3.9545, S D=.7352), t(43)=.880, \mathrm{p}=.384$. In general, case-based discussions led to a higher level of cognitive presence than non-case-based discussion, except for exploration.

A paired-samples t-test was performed to compare perceived learning and satisfaction between case-based and non-case-based discussions. In terms of perceived learning outcomes, no significant difference was found between case-based discussion $(M=4.00, S D=.84)$ and non-case-based discussion $(M=3.84, S D=.96), t(43)=1.636, \mathrm{p}>.05$. However, students reported higher level of satisfaction on case-based discussion $(M=4.0909, S D=.7721)$ than on non-case-based discussion $(M=3.7955$, $S D=.8235), t(43)=3.301, \mathrm{p}<.05$. In general, these results suggest that students tend to have a higher level of satisfaction when they participate in the case-based discussion than non-case-based discussions. 
In addition, comments in the open-ended survey questions revealed that students valued case discussions as meaningful and engaging. Qualitative results revealed that students enjoyed participating in case-based discussions and said that using the concepts that we learned from our readings and applying them to real life problems helped them get a better understanding of the concepts and how to use them. Students commented that, "case-based discussions helped construct explanations, solutions, and reflections on course content to understand fundamental concepts in this class." These results show that it is important to give students an authentic task such as a case or a problem to solve followed by PIM prompts can make discussions relevant to their learning. Sadaf and Olesova (2017) concluded that moving discussions through the stages of cognitive presence may lead to high levels of learning as each stage offers a process that encourages knowledge construction through deep levels of discourse among students.

\section{CONCLUSION}

Achieving high levels of cognitive presence is often the goal of online discussions. This study contributes to the limited body of knowledge on the notion that discussions can reach high levels of cognitive presence, progressing from triggering to integration and resolution phases, when instructors require students to provide a solution to cases or lead a discussion to a meaningful resolution of ideas. Looking at the results, one may conclude that students are more satisfied and perceive to achieve high levels of cognitive presence using case-based discussions. In this regard, online instructors can use case-based discussions that ask students to explore the problems, find and justify their solutions to facilitate high-levels of cognitive presence that may lead to deeper constructivist learning among students. Overall, the findings in this study are valuable because they contribute to further effective design of online asynchronous discussions through the use of case-based real-world scenarios for learning a specific discipline.

This study has some limitations that may lead to future research efforts. First, this study is limited in generalizability of findings due to small sample size and participants representing only one program and university. Follow-up studies could utilize large sample size with data collected across programs or institutions to further refine the results and implications of this study. In addition, research investigating the relationship between the levels of question prompts and the levels of cognitive presence in students' postings and the discourse facilitated in follow-up responses would be a promising direction for future studies.

\section{REFERENCES}

Darabi, A., Liang, X., Suryavanshi, R., \& Yurekli, H. (2013). Effectiveness of online discussion strategies: A meta-analysis. American journal of distance education, 27(4), 228-241.

Ertmer, P.A., \& Koehler, A.A. (2014). Online case-based discussions: Examining coverage of the afforded problem space. Educational Technology Research and Development, 62(5), 617-636.

Ertmer, P. A., \& Stepich, D. A. (2002). Initiating and maintaining meaningful case discussions: Maximizing the potential of case-based instruction. Journal on Excellence in College Teaching, 13(2/3), 5-18.

Garrison, D.R., Anderson, T., \& Archer, W. (2001). Critical thinking, cognitive presence, and computer conferencing in distance education. The American Journal of Distance Education, 15(1), 7-23.

Jonassen D.H. (2010). Learning to Solve Problems: A Handbook. Routledge, NewYork.

Miles, M. B., \& Huberman, A. (1994). Qualitative data analysis: An expanded sourcebook.

Nistor, N., \& Neubauer, K. (2010). From participation to dropout: Quantitative participation patterns in online university courses. Computers \& Education, 55(2), 663-672.

Richardson, J. C., Sadaf, A., \& Ertmer, P. A. (2013). Relationship between types of question prompts and critical thinking in online discussions. In Educational communities of inquiry: Theoretical framework, research and practice (pp. 197-222). IGI Global.

Rourke, L., \& Kanuka, H. (2009). Learning in communities of inquiry: A review of the literature. Journal of Distance Education, 23(1), 19-48.

Sadaf, A., \& Olesova, L. (2017). Enhancing cognitive presence in online case discussions with questions based on the practical inquiry model. American Journal of Distance Education, 31(1), 56-69.

Yew, E. H., \& Schmidt, H. G. (2012). What students learn in problem-based learning: A process analysis. Instructional Science, 40(2), 371-395. 